\title{
A biomechanical evaluation of taping and bracing in reducing knee joint translation and rotation
}

\author{
KYLE ANDERSON, EDWARD M. WOJTYS, ${ }^{*}$ MD, PETER V. LOUBERT, PhD, PT, ATC, \\ AND RUSSELL E. MILLER, PT, ATC
}

\author{
From Medsport, and the section of Orthopaedic Surgery, University of Michigan, \\ Ann Arbor, Michigan
}

\begin{abstract}
We used five randomly selected cadaver specimens to evaluate the Anderson Knee Stabler and the Lenox Hill Knee Brace, individually and in combination with an anterior cruciate ligament protective tape method. Reduction of total laxity, as well as a defined pathologic anterior-posterior translation and internal-external rotation, was tested after the anterior cruciate and medial collateral ligaments of the specimens had been sectioned. Displacements were produced pneumatically; loads were applied to the tibia with the knee in $50^{\circ}$ of flexion.

The tape and Lenox Hill Brace combination showed the greatest reduction in both anterior-posterior translation and internal-external rotation. The Lenox Hill Brace and the tape method used individually both restricted anterior-posterior translation and internal-external rotation better than the Stabler Brace alone. This study provides objective evidence of the restraining capabilities of these protective systems that may prove to be beneficial in the clinical setting.
\end{abstract}

The incidence and recurrence of knee injuries in athletic competition has created a large market for protective measures to improve knee stability. High school, college, and professional athletic teams spend large amounts of money on devices and materials designed to provide these measures. Among the most popular means of protection are athletic tape, prophylactic braces, functional braces, and quite commonly, combinations of tape and a brace. At the University of Michigan, over $\$ 50,000$ is spent annually on athletic tape.

* Address correspondence and reprint requests to: Edward M. Wojtys, MD, University of Michigan, Medsport, P. O. Box 363, Ann Arbor, MI 48106-0363.
Literally dozens of braces produced by various manufacturers are currently available, but only at a considerable expense. Unfortunately, neither the practice of taping nor bracing has sufficient objective justification for their extensive use.

Despite the cost of taping, very little is known about its effectiveness as a ligament support in healthy or injured knees, or of its role in knee joint kinematics. In fact, the authors are aware of only one study evaluating the effectiveness of taping with or without braces; this work was reported by Roser et al. ${ }^{18}$ in 1971 . They suggested that the main benefit of taping unstable knees was psychological and that increased stability could not be demonstrated. Their report was rather pessimistic, but it does point out the lack of research in this area.

Prophylactic bracing is also a controversial area. ${ }^{2,9,12,21}$ While some studies have supported their use in restricted circumstances, ${ }^{7,20}$ others have actually suggested that prophylactic bracing may increase the rate of injury at the knee $^{19}$ and ankle joint. ${ }^{10}$

Functional knee bracing, which is commonly used in the treatment of ACL-deficient or ACL-reconstructed knees, is no less controversial. While plenty of subjective testimonials of protection are available, ${ }^{3,8,14,15,16,22}$ the results of independent objective studies ${ }^{3,5,6,13,17,23,24}$ are not as encouraging.

Given the lack of objective support, the purpose of this investigation was to evaluate the biomechanics of anteriorposterior (AP) tibiofemoral translation and internal-external (IE) rotation and the effect of an ACL-protective knee taping method, used alone and in combination with a functional or prophylactic knee brace. The braces used were the Lenox Hill (Lenox Hill Brace Inc, Long Island City, NY) and the Anderson Knee Stabler (Omni Scientific Inc, Lafayette, IL). The authors chose to evaluate these two braces because of their extensive use in competitive sports. The Anderson Knee Stabler was designed to provide support 
mainly to the collateral ligaments of the knee, ${ }^{1}$ and it is often used as a prophylactic brace. Unfortunately, it has been suggested that there is a possible association between the use of the brace and an increased rate of knee injuries, including ACL tears. ${ }^{19,21}$ With these factors in mind, we evaluated the reductions of pathologic AP translation and IE rotation provided by taping, braces, and a combination of both in knees with a torn ACL and medial collateral ligament (MCL).

\section{MATERIALS AND METHODS}

Testing was carried out on the hip-disarticulated lower extremities of five fresh-frozen human cadavers. Specimens were the same as those randomly selected for a previous study that involved complete sectioning of the ACL and MCL. ${ }^{24}$ Because the present study was an extension of the previous work and statistical comparisons demonstrated no significant tissue loosening had occurred between these studies, displacement data obtained before ligament sectioning were available for analysis. This reference allowed for the definition of the variable "pathologic displacement." Pathologic displacement was defined as the amount of displacement greater than that produced when the intact limb with no brace or tape was tested. Percent reduction in pathologic displacement was calculated by the following formula: Percent Reduction in Pathologic Displacement $=[1-(D-N L /$ $\mathrm{RV}-\mathrm{NL}$ ) $] \times 100$ where $\mathrm{D}=$ displacement from a given test measurement, $\mathrm{NL}=$ displacement in the intact specimen, $\mathrm{RV}=$ displacement in the limb with ligaments transected and no restraint.

Specimens ranged in age from 57 to 75 years (mean, 65). There were three right limbs and two left limbs. All of the limbs were examined clinically before the experiments and were found to be stable and without visible scars, deformities, or abnormal range of motion. All specimens were kept frozen at $-20^{\circ} \mathrm{C}$ except during preparation and testing. The limbs were removed from the freezer the day before each test session. Testing was not begun until the limbs were thoroughly defrosted, as evidenced by a smooth, easy to complete range of motion.

Specimens were prepared for testing by cutting through the femur and the soft tissues of the thigh at the level of the lesser trochanter, reaming the femur, and cementing a threaded rod ( 0.5 inch diameter) into the medullary canal, leaving approximately 6 inches available for anchoring to the testing jig. We then cut through the tibia and soft tissues of the leg immediately proximal to the medial malleous, reamed the tibia, and cemented a spline into the medullary canal, reinforcing it with cross-bolts to protect against failure during torsional loads. Next, we drilled a $3 / 8$-inch diameter hole, anterior to posterior, through the tibia at the level at the tibial tubercle and bolted $a 3 / 8$-inch diameter threaded dowel through the hole so that it projected posteriorly through the soft tissues. Last, we inserted two cancellous bone screws, diagonally and obliquely, through the distal end of the femur (Fig. 1). Neither the screws nor the dowel impeded the motion of the knee joint.

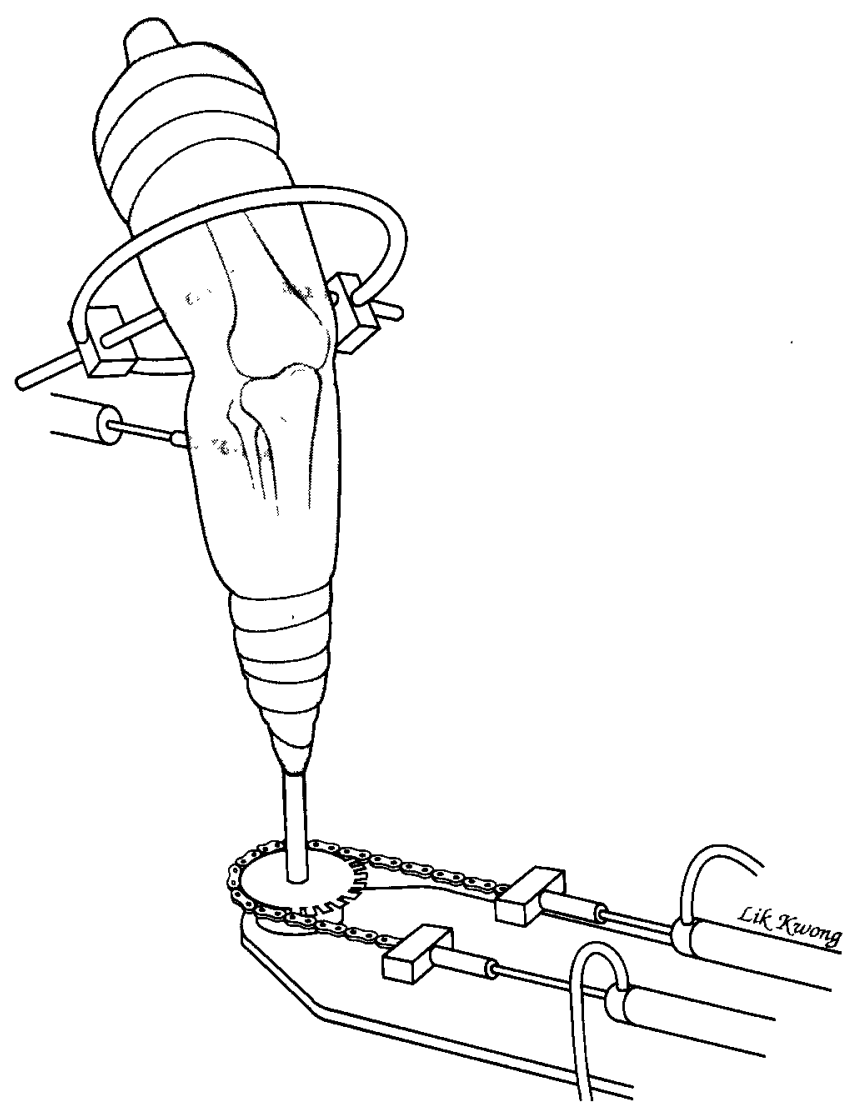

Figure 1. Testing apparatus and mounted specimen without a brace.

Before testing, each specimen was positioned in the testing jig using the center of rotation of the knee as a reference to ensure consistent placement of specimens. The testing apparatus, data acquisition, and procedure are described in a previous study. ${ }^{24}$ All loads were applied as impact loads and were maintained until the displacement had ceased and the system had reached equilibrium. Anterior-posterior loads of $125 \mathrm{~N}$ were imposed on the tibia through the threaded dowel in the proximal tibia and were applied with a pneumatic cylinder in series with a load cell. The AP loading system was connected, in parallel, to a linear potentiometer. The load cell was calibrated on an Instron (Instron Corp, Canton, MA) materials testing machine and was used to measure AP forces. The linear potentiometer measured anterior and posterior displacements.

Rotation was produced through a bicycle sprocket (Fig. 1) coupled to the tibial spline. A bicycle chain was wrapped halfway around the sprocket with its ends attached to pneumatic cylinders in series with the load cells. This system provided a constant lever arm producing rotational loads of $12 \mathrm{Nm}$, independent of the extent of displacement. The force measurements were multiplied by the lever arm to calculate torsional loads. Rotational displacements were measured with a ten-turn potentiometer connected to the rotating sprocket. 
All data were recorded directly on a microcomputer through a data acquisition system and sampled at $100 \mathrm{~Hz}$. Hardware control and data reduction were performed by a custom program written in ASYST (ASYST Software Technologies, Inc, Rochester, NY). Limbs were placed in the testing jig with the knee in $50^{\circ}$ of flexion. Taping, brace application, and all testing were performed in this position. Fifty degrees of flexion was chosen because the clinical protocol for taping requires this position. The braces used in this study could also be applied in this position. Practical reasons and the need to minimize the risk of undue tissue fatigue prevented testing of other joint positions.

In the test procedure, we started the acquisition of data by triggering the computer and then opening the appropriate pneumatic valves to supply the loads. The computer sounded a bell at the beginning and end of an 8-second interval during which the translational or the rotational test was performed. A single trial was used for each test condition. Reliability testing provided a reliability coefficient of 0.99 for both translation and rotation, indicating that a single repetition would be sufficiently representative. Translational tests were performed by loading anteriorly first, then posteriorly. Rotational tests were performed by loading internally first and then externally. Displacement values for each trial were recorded as the displacement at the first occurrence of the target load.

The method of taping used at the University of Michigan Athletic Department to support ACL-deficient knees is a combination of techniques used by others in the athletic training field, but not specifically identified elsewhere in the literature. This method is designed to limit anterior translation of the tibia as well as to provide medial and lateral support to decrease varus and valgus angulation of the knee.

After appropriate preparation with tape adherent and protection of the popliteal space, the tape was applied as shown in Figure 2. First, anchor strips were applied to the thigh and leg (Fig. 2A). Then, a series of strips forming an "X" pattern centered at the midjoint line were applied to the medial and lateral aspects of the knee (Fig. 2B). Next, a series of strips formed a spiral pattern designed to augment A-P stability without limiting patella movement (Fig. 2C). Finally, an ACL-protective strip was applied to capture the proximal tibia and decelerate full extension of the knee (Fig. 2D).

Before and after tests of the restraints, each specimen was tested without a restraint to serve as a control and to monitor for soft tissue loosening during the test procedures. Paired $t$-test comparisons were made to examine this pre- and posttest control relationship. These comparisons indicated that there was no significant change in AP translation and a $3 \%$ increase in rotation $(P=0.032)$. Because the tissue loosening that occurred was small relative to the changes caused by the interventions, we felt that the most appropriate reference value would be obtained by averaging the preand posttest results of the unprotected controls. Data were standardized to this reference value, allowing comparisons to be made between restraints over several specimens.
A $95 \%$ confidence interval was used to demonstrate that in each case application of a restraint resulted in a significant reduction in tibiofemoral displacement relative to the control. The control values for reduction of displacement were used as the reference point and the confidence interval tested whether all reductions of displacement were significantly greater than the control values.

One-way analysis of variance and covariance with repeated measures were performed to test the significance of differences between the various restraint conditions and combinations.

Paired $t$-tests were performed to compare each restraint condition to the others. The chosen level of significance was $P<0.05$. Because multiple comparisons were made between the various testing conditions, a Bonferroni adjustment for simultaneous significance of the comparisons was used. Therefore, to achieve an overall $P$ value of 0.05 , only those individual comparisons with $P$ values less than 0.005 met the criteria for simultaneous significance.

\section{RESULTS}

All testing conditions using the braces, tape, or combinations resulted in a significant reduction in both AP translation and IE rotation when compared to the averaged control (Table 1). Results of the analysis of variance showed that significant differences between the various restraint conditions existed: [F statistic $=22.23, P<0.005, d f=(4,4)]$.

Percent reductions in pathologic displacement and rotation are shown in Table 2. Significance levels of comparisons between the conditions for translation and rotation are reported in Table 3.

The tape and Lenox Hill brace combination performed statistically better than any other individual restraint or combination in reducing AP translation and IE rotation. The differences between tape, the Lenox Hill Brace, and the Stabler Brace when used individually were not statistically significant nor were they different from the combination of tape plus Stabler Brace.

\section{DISCUSSION}

The reduction of translation and rotation provided by the tape plus Lenox Hill Brace combination was clearly greater than any other restraint condition. This was not surprising since Roser et al. ${ }^{18}$ reported that the combination of taping plus the Palmer brace (Quik-Cold Inc, Moberly, MO) improved anteroposterior stability.

Although comparisons between the individual restraints did not meet the chosen criterion for significance, the authors are confident that, compared to the Stabler Brace alone, both the Lenox Hill Brace and the tape method will provide greater restriction to translation and rotation. This conclusion was to be expected given the design and intended purpose of the Stabler Brace. Unfortunately, we were not able to test for varus-valgus instability where the Stabler would have been expected to perform much better than it did for AP translation and IE rotation. 


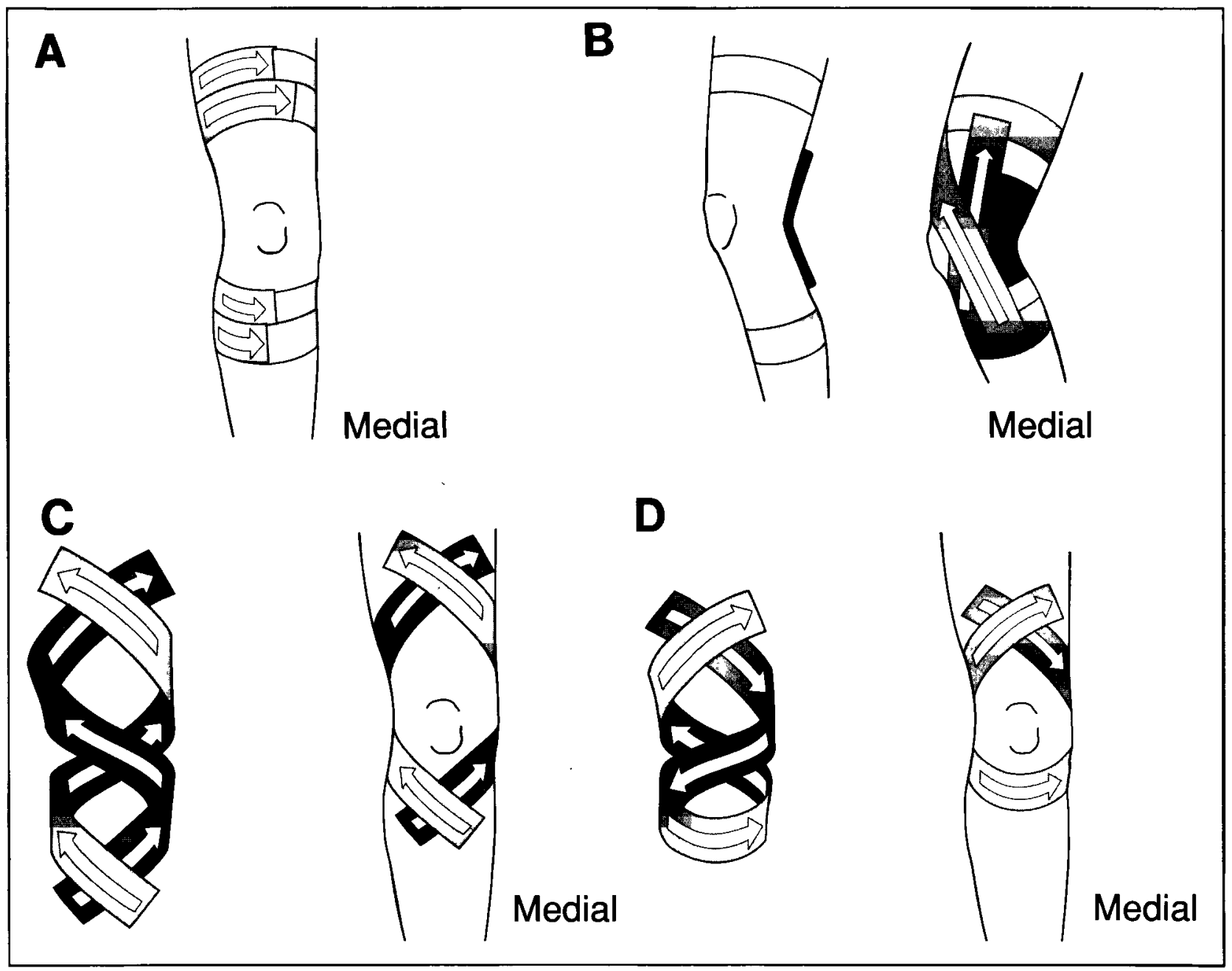

Figure 2. Diagrams of the taping method used as shown on a left knee. A, the initial step in taping involved applying anchoring strips around the thigh and leg. $B$, the second series of tape strips formed an $X$ pattern on the medial side of the knee. C, the third series of strips were spiraled distal to proximal in opposite directions and crisscrossed in the midpopliteal space. D, the ACL spiral strips were applied beginning on the anterior thigh angling distally and medially, then spiraling around the leg before turning posteriorly and superiorly to finish laterally on the anterior thigh.

TABLE 1

Total absolute measurements of rotation and translation in five specimens

\begin{tabular}{lrrrrrrr}
\hline \multicolumn{1}{c}{ Test } & $\begin{array}{c}\text { No brace } \\
\text { (before) }\end{array}$ & \multicolumn{1}{c}{ Tape } & Tape + Lenox & Lenox & Stabler & $\begin{array}{c}\text { Tape }+ \\
\text { Stabler }\end{array}$ & $\begin{array}{c}\text { No brace } \\
\text { (after) }\end{array}$ \\
\hline Rotation (deg) & 78.10 & 67.70 & 54.75 & 67.05 & 73.85 & 66.70 & 78.95 \\
Translation (mm) & 28.80 & 18.25 & 14.65 & 22.85 & 27.85 & 16.30 & 29.60 \\
Rotation & $\mathbf{5 5 . 6 2}$ & 44.61 & 35.37 & 46.12 & 50.83 & 39.32 & 57.04 \\
Translation & 19.63 & 18.16 & 11.80 & 17.28 & 18.04 & 16.19 & 19.62 \\
Rotation & 63.51 & 46.96 & 37.30 & 53.52 & 58.72 & 44.53 & 65.03 \\
Translation & 27.50 & 18.78 & 13.63 & 19.00 & 24.04 & 19.03 & 25.81 \\
Rotation & 84.60 & 68.72 & 58.55 & 73.34 & 81.58 & 63.18 & 89.30 \\
Translation & 37.52 & 30.01 & 18.80 & $\mathbf{2 7 . 4 5}$ & 35.60 & 26.30 & 38.29 \\
Rotation & 107.61 & 100.39 & 77.54 & 96.28 & 95.27 & 91.15 & $\mathbf{1 1 1 . 5 7}$ \\
Translation & 31.10 & 28.08 & 22.02 & 27.39 & 29.76 & 27.47 \\
\hline
\end{tabular}


TABLE 2

Percent reduction of pathologic displacements in five specimens

\begin{tabular}{lccccc}
\hline Specimen & Tape & $\begin{array}{c}\text { Tape }+ \\
\text { Lenox }\end{array}$ & Lenox & Stabler & $\begin{array}{c}\text { Tape }+ \\
\text { Stabler }\end{array}$ \\
\hline 240 & & & & & \\
$\quad$ Translation (\%) & 58.6 & 77.8 & 34 & 7.2 & 69 \\
$\quad$ Rotation (\%) & 75.1 & 164.8 & 79.6 & 32.4 & 82 \\
238 & & & & & \\
$\quad$ Translation & 15.5 & 83.9 & 27.4 & 18.9 & 36.7 \\
$\quad$ Rotation & 66.8 & 119.6 & 58.2 & 31.4 & 97 \\
239 & & & & & \\
$\quad$ Translation & 43.8 & 72.5 & 42.6 & 14.5 & 42.5 \\
$\quad$ Rotation & 177.2 & 276 & 110 & 56.81 & 202 \\
241 & & & & & \\
$\quad$ Translation & 30.1 & 72.9 & 39.9 & 8.8 & 44.3 \\
$\quad$ Rotation & 68.7 & 107 & 51.2 & 20.2 & 89.5 \\
242 & & & & & \\
$\quad$ Translation & 14 & 41.5 & 17.1 & 6.4 & 16.76 \\
$\quad$ Rotation & 18.8 & 48.4 & 27.3 & 29.35 & 37.8 \\
$\quad$ Average & & & & & \\
$\quad$ Translation & 21.0 & 43.7 & 20.4 & 6.2 & 26.6 \\
$\quad$ Rotation & 18.2 & 34.3 & 15.5 & 8.7 & 24.0 \\
\hline
\end{tabular}

Two important limitations must be taken into account when interpreting this data. The first is that the load levels used to test knee laxity in this study were much lower than those levels anticipated in an in vivo circumstance, particularly those that would result in a joint injury. ${ }^{3,8,12,16}$ Beck et $a .^{4}$ found that as the force level increased, the effectiveness of functional knee braces in controlling anterior tibial translation decreased. Markolf et al. ${ }^{11}$ stated that laxity measurements were best observed under high loads (200 N), while knee stiffness changes were best demonstrated at low loads (100 N or less). Thus, at high load levels the displacements would be expected to be much greater. The lower load levels used in this investigation provided consistency and reliability in the procedure and were necessary to avoid damaging the limb preparations.

Another important limitation to consider is the lack of active muscle tension in the cadaveric model used in this study. Under normal conditions, tension produced by muscles that cross the joint would be expected to decrease the displacements at a given load. The ACL/MCL-deficient cadaveric model is an example of an unstable knee where active muscle tension does not contribute to knee stability. This model allows specific isolation of the mechanical component of the restraint and it represents a condition where dependence on the restraint is maximal.

Before extrapolating the results of this study to clinical practice, some additional considerations are needed. In particular, loosening and slippage of tape or a brace is a common problem encountered during activity. Brace slippage can decrease its effectiveness and continues to be a major patient complaint. ${ }^{8,12}$ With activity, tape may stretch and perspiration may loosen the grip, rendering it ineffective as well. None of these situations were present in this study. Because of these factors, some of the results may be overly optimistic when considering their actual clinical effectiveness.

Another important consideration is the role that sensory feedback and proprioception may play in determining the magnitude of reduction of displacement that taping or bracing may provide. While little is known about the effects of these restraints on proprioception, one can be certain that tactile information received from around the joint is affected. One can speculate that there would be a beneficial increase in the athlete's motor control system. Branch et al. ${ }^{5}$ studied the EMG patterns of muscles crossing the knee joint in ACL-deficient knees with and without braces and concluded that the firing patterns of the quadriceps, hamstrings, and gastrocnemius muscles did not change. While this data was interpreted to mean that no change in proprioception occurred, the total and peak activity of the quadriceps and hamstring muscles did change with bracing, indicating a possible effect and suggesting the need for further research.

In some circumstances, all of our defined pathologic displacement was eliminated and even some the tibiofemoral motion present with intact ligaments was restrained (e.g., Table 2, Cadaver $239,177.2 \%$ reduction in pathologic IE rotation with tape). This raises the question of how much restraint is necessary and appropriate for controlling knee joint kinematics. If mobility is overly restricted, one would anticipate a decreased range of motion and altered kinematics. This could lead to accelerated rates of joint surface

TABLE 3

Comparison of mean percent reduction

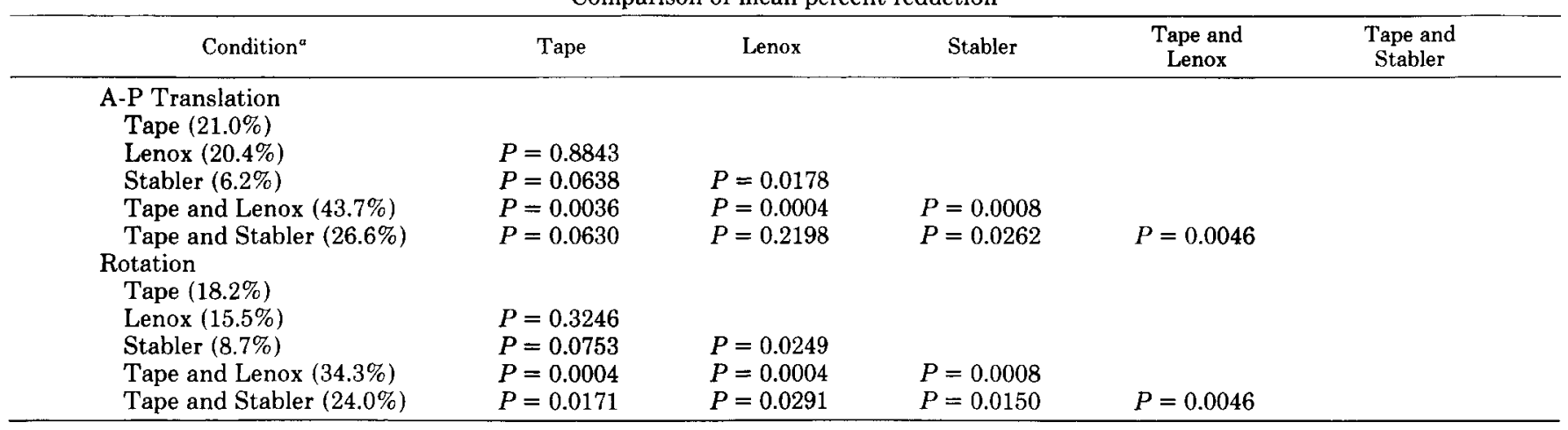

${ }^{a}$ Average percent reduction given in parentheses. 
degeneration or other complications. Thus, our goals for controlling abnormal tibiofemoral translation must account for the possibility of undesired overrestraint. The ideal brace is one that permits full normal mobility, but restricts any motion beyond that.

This study evaluated the purely mechanical effects of braces, tape, and combinations of tape and a brace on the AP translation and IE rotation of knees with complete ACL and MCL ruptures. It indicates that athletic tape or brace restraints do have a mechanical effect in reducing knee instability. The combination of tape plus the Lenox Hill Brace provided more restraint than any other condition. Whether these effects, when combined with factors encountered in a normal physiologic environment are actually beneficial remains controversial and requires further investigation.

\section{ACKNOWLEDGEMENTS}

This work was supported in part by the Orthopaedic Research and Education Foundation, Bristol Myers/Squibb Zimmer Research Excellence Award. The authors also acknowledge the assistance of Sarafin Samson, David Viviano, and Dennis Kayner in the design and fabrication of the experimental systems.

\section{REFERENCES}

1. Anderson G, Zeman SC, Rosenfeld RT: The Anderson Knee Stabler. Physician Sportsmed 7(6): 125-127, 1979

2. Baker BE, VanHanswyk E, Bogosian S, et al: A biomechanical study of the static stabilizing effect of knee braces on medial stability. Am J Sports Med 15: 566-570, 1987

3. Bassett GS, Fleming BW: The Lenox Hill Brace in anterolateral rotatory instability. Am J Sports Med 11: 345-348, 1983

4. Beck C, Drez D, Young J, et al: Instrumented testing of functional knee braces. Am J Sports Med 14: 253-256, 1986
5. Branch TP, Hunter R, Donath M: Dynamic EMG analysis of anterior cruciate deficient legs with and without bracing during cutting. Am J Sports Med 17: 35-41, 1989

6. Branch TP, Hunter R, Reynolds P: Controlling anterior tibial displacement under static load: A comparison of two braces. Orthopedics 11: 12491252,1988

7. Brown TD, Van Hoeck JE, Brand RA: Laboratory evaluation of prophylactic knee brace performance under dynamic valgus loading using a surrogate leg model. Clin Sports Med 9: 751-762, 1990

8. Colville MR, Lee CL, Ciullo JV: The Lenox Hill brace: An evaluation of effectiveness in treating knee instability. Am J Sports Med 14: 257-261, 1986

9. Garrick JG, Requa RK: Prophylactic knee bracing. Am J Sports Med 15: 471-476, 1987

10. Grace TG, Skipper BJ, Newberry JC, et al: Prophylactic knee braces and injury to the lower extremity. J Bone Joint Surg 70A: 422-427, 1988

11. Markolf $\mathrm{KL}$, Kovan A, Amstutz HC: Measurements of knee stiffness and laxity in patients with documented absence of the anterior cruciate ligament. J Bone Joint Surg 66A: 242-252, 1984

12. Mishra DK, Daniel DM, Stone ML: The use of functional knee braces in the control of pathologic anterior knee laxity. Clin Orthop 241: 213-220, 1989

13. Mortensen WW, Formen K, Focht $L$, et al: An in vitro study of functional orthoses in ACL disrupted knees. Trans Orthop Res Soc 13: 520, 1988

14. Nicholas JA: Bracing the anterior cruciate ligament deficient knee using the Lenox Hill derotation brace. Clin Orthop 172: 137-142, 1983

15. Nicholas JA: The five-one reconstruction for anteromedial instability of the knee. J Bone Joint Surg 55A: 899-922, 1973

16. Noyes FR, Mooar PA, Matthew DS, et al: The symptomatic anterior cruciate-deficient knee. Parts I \& II. J Bone Joint Surg 65A: 154-174, 1983

17. Rink PC, Scott RA, Lupo RL, et al: A comparative study of functional bracing in the anterior cruciate deficient knee. Orthop Rev 18: 719-727, 1989

18. Roser LA, Miller SJ, Clawson DK: Effects of taping and bracing on the unstable knee. Northwest Med 70: 544-546, 1971

19. Rovere GD, Haupt HA, Yates CS: Prophylactic knee bracing in college football. Am J Sports Med 15: 111-116, 1987

20. Sitler M, Ryan J, Hopkinson W, et al: The efficacy of a prophylactic knee brace to reduce knee injuries in football. A prospective, randomized study at West Point. Am J Sports Med 18: 310-315, 1990

21. Teitz CC, Hermanson BK, Kronmal RA, et al: Evaluation of the use of braces to prevent injury to the knee in collegiate football players. $J$ Bone Joint Surg 69A: 2-9, 1987

22. Wellington $P$, Stother IG: The Lenox Hill derotation brace in chronic posttraumatic instability of the knee. Injury 15: 242-244, 1984

23. Wojtys EM, Goldstein SA, Redfern $M$, et al: $A$ biomechanical evaluation of the Lenox Hill knee brace. Clin Orthop 220: 179-184, 1987

24. Wojtys EM, Loubert PV, Samson SY, et al: Use of a knee-brace for control of tibial translation and rotation. $J$ Bone Joint Surg 72A: 1323-1329, 1990 